University of Wollongong

Research Online

Faculty of Social Sciences - Papers (Archive) Faculty of Arts, Social Sciences \& Humanities

2014

The retention, revival, and subjugation of Indigenous fire knowledge through agency fire fighting in eastern Australia and California

Christine Eriksen

University of Wollongong, ceriksen@uow.edu.au

Don L. Hankins

California State University

Follow this and additional works at: https://ro.uow.edu.au/sspapers

Part of the Education Commons, and the Social and Behavioral Sciences Commons

Research Online is the open access institutional repository for the University of Wollongong. For further information contact the UOW Library: research-pubs@uow.edu.au 


\title{
The retention, revival, and subjugation of Indigenous fire knowledge through agency fire fighting in eastern Australia and California
}

\author{
Abstract \\ This article explores the potential impact of training and employment with wildfire management agencies \\ on the retention of Indigenous fire knowledge. It focuses on the comparative knowledge and experiences \\ of Indigenous Elders, cultural practitioners, and land stewards in connection with "modern" political \\ constructs of fire in New South Wales and Queensland, Australia, and California in the United States of \\ America. This article emphasises the close link between cross-cultural acceptance, integration of \\ Indigenous and agency fire cultures, and the ways in which knowledge types are shared or withheld. While \\ agency fire fighting provides an opportunity for Indigenous people to connect and care for country, it \\ simultaneously allows for the breaking of traditional rules surrounding what knowledge is shared with \\ whom in the context of Indigenous cultural burning. By highlighting how privilege intersects with ethnicity, \\ class, gender and age, this article demonstrates how greater cross-cultural acceptance could aid ongoing \\ debates on how to coexist with wildfire today.

\section{Keywords} \\ fighting, fire, indigenous, agency, retention, revival, eastern, australia, california, knowledge, subjugation

\section{Disciplines} \\ Education | Social and Behavioral Sciences

\section{Publication Details} \\ Eriksen, C. \& Hankins, D. L. (2014). The retention, revival, and subjugation of Indigenous fire knowledge \\ through agency fire fighting in eastern Australia and California. Society and Natural Resources, 27 (12), \\ 1288-1303.
}


Eriksen, C. \& Hankins, D. L. (2014) The retention, revival and subjugation of indigenous fire knowledge through agency fire fighting in eastern Australia and California, USA.

Society and Natural Resources, 27(12), pp.1288-1303.

The Retention, Revival and Subjugation of Indigenous Fire Knowledge through

Agency Fire Fighting in Eastern Australia and California, USA

\begin{abstract}
This paper explores the potential impact of training and employment with wildfire management agencies on the retention of Indigenous fire knowledge. It focuses on the comparative knowledge and experiences of Indigenous Elders, cultural practitioners, and land stewards in connection with 'modern' political constructs of fire in New South Wales and Queensland, Australia and California, USA. This paper emphasises the close link between cross-cultural acceptance, integration of Indigenous and agency fire cultures, and the ways in which knowledge types are shared or withheld. While agency fire fighting provides an opportunity for Indigenous people to connect and care for country, it simultaneously allows for the breaking of traditional rules surrounding what knowledge is shared with whom in the context of Indigenous cultural burning. By highlighting how privilege intersects with ethnicity, class, gender and age, this paper demonstrates how greater cross-cultural acceptance could aid ongoing debates on how to coexist with wildfire today.
\end{abstract}

Keywords Indigenous knowledge retention, wildland fire fighting, trust, Australia, USA.

The multi-layered and at times intangible cultural importance of fire extends its roots far into the past. Fire is an integral component of most Indigenous cultures in both Australia and North America (Stewart et al. 2002; Miller and Davidson-Hunt 2010; Gammage 2011). It extends beyond basic domestic needs for responsible environmental stewardship based upon philosophies of reciprocal relationships at 
Eriksen, C. \& Hankins, D. L. (2014) The retention, revival and subjugation of indigenous fire knowledge through agency fire fighting in eastern Australia and California, USA.

Society and Natural Resources, 27(12), pp.1288-1303.

scales from the individual to the universe. Fire has played a key role in the land

management practices of Aboriginal Australians and Native Americans for millennia

(Lewis 1989, 1993; Lewis and Ferguson 1988; Pyne 1997; Anderson 2005;

Christianson et al. 2012). Colonisation introduced a new paradigm of law into

Indigenous cultures, although it should be noted that colonial processes were uneven

in time and space. Colonial interests in both Australia and the USA disrupted

Indigenous use of fire through the removal of people from their lands and policy

prohibition. In place of traditional Indigenous fire knowledge, policies derived from

state and federal agencies established around the concept of fire suppression or fire

fighting has become a societal norm, which today forms a baseline amongst many

Indigenous and non-Indigenous people in these two regions. As a consequence, many

Indigenous people employed to work with fire are today predominantly trained within

the Eurocentric ${ }^{1}$, hierarchical and patriarchal ${ }^{2}$ colonial notion of fire fighting. Fire

fighting agencies and men are therefore likely to be their main source of fire

knowledge.

This paper explores the potential impact of training and employment with wildfire management agencies on the retention of Indigenous fire knowledge. It is based on insights gained from research with Native Americans in California and Aboriginal Australians in New South Wales (NSW) and Queensland (QLD) over the past decade. We focus on the comparative knowledge and experiences of Indigenous Elders,

\footnotetext{
${ }^{1}$ Dominant Western environmental views (e.g. fire suppression) act as powerful narratives in the condemnation of Indigenous fire knowledge and the concept of humans as part of nature. 'By applying universalised Eurocentric knowledge, other knowledges are rendered silent, are ignored, devalued and/or undermined so that Eurocentric knowledges only hear, see . . . and engage with themselves' (Suchet 2002, 149; see also Brody 2002).

${ }^{2}$ The ways in which gender regimes are embedded in social structures is reflected in the inclusion of women into the ranks of fire fighting on the proviso that they meet the perceived non-emotional, nononsense, non-compromising masculine way of engaging with risk. For more detail and gender disaggregated statistics see, e.g., Davidson and Black (2001); Childs (2006); www.i-women.org; Pacholock (2009); Eriksen (in press).
} 
Eriksen, C. \& Hankins, D. L. (2014) The retention, revival and subjugation of indigenous fire knowledge through agency fire fighting in eastern Australia and California, USA. Society and Natural Resources, 27(12), pp.1288-1303.

cultural practitioners, and land stewards to examine four key questions. How does

Indigenous fire knowledge connect with 'modern' political constructs of fire (Jensen

and McPherson 2008)? Does the mixing of fire cultures change the outlook and

practices of wildfire management agencies or the cultural laws of Indigenous

burning? Does the knowledge or ignorance of cultural or gendered landscapes, such

as Indigenous sacred and ceremonial sites off-limits to women or men, effect agency

policy or the on-the-ground practices of fire fighters? Which issues impede cross-

cultural acceptance? We structure the examination of these four questions in the

subsequent sections through an initial discussion of the historical and political context

that surrounds cultural implications of burning and a presentation of the research

methodology.

Indigenous burning practices are distinguished from agency fire management in the context of traditional law, objectives and the right to burn. At the core of Indigenous eco-cultural fire processes is recognition of the interrelated and interdependent aspects of fire that follow the laws of the land (nature). Traditional law and lore are rooted in the landscape and stories that define a given culture (Black, 2011). By 'lore' we refer to story, whereas Indigenous law is coded in the lore. The landscape will convey its need for burning based on factors such as the accumulation of dead plant materials or the decline in resource conditions. Such knowledge may be encoded in the stories of a region. These stories may also convey the penalties for not following the laws of the land, as often depicted in Aboriginal fire paintings. This knowledge forms how a culture interacts with fire and more specifically how, what, where, when, and why burning occurs spatially and temporally for cultural and environmental 
Eriksen, C. \& Hankins, D. L. (2014) The retention, revival and subjugation of indigenous fire knowledge through agency fire fighting in eastern Australia and California, USA.

Society and Natural Resources, 27(12), pp.1288-1303.

reasons. In most traditional ${ }^{3}$ Indigenous societies it continues to be the responsibility

of fire knowledge keepers and practitioners to maintain the law and the specifics required to 'regulate' and implement burning within particular local domains of governance (Stewart et al. 2002; White 2004; Gammage 2011). Thus fire among Indigenous cultures is a complex affair, which has been muddled by the laws, policies and practices of colonisation (Claudie 2009).

Yet at the root of Aboriginal Australian and California Indian communities, Indigenous laws have continued to operate outside the colonial laws of present-day Australia and USA. In some regions of northern and central Australia Indigenous law and practice are still applied through fires ranging in scale from individual plants to fire at a landscape scale (TKRP 2011; Bird et al. 2004; Vigilante et al. 2009). In California this happens at a fine localised scale at present (Hankins 2009; Lake 2007; Hawkes 2011), but it was significant historically, occurring across the scales from individual plants to the landscape (Lewis 1993; Anderson 2005; Stephens et al. 2007). These examples illustrate a chain of knowledge from which to contrast Indigenous and non-Indigenous fire use and management practices.

From our experience and observations working with Indigenous communities in Australia and California during the past decade, the knowledge of fire frequently persists in varying formats among Indigenous women and men who are either cultural practitioners or land stewards within agencies founded on Eurocentric colonial notions, such as fire fighting. This is not to say that the knowledge does not persist outside of contemporary fire fighting careers or that other avenues of knowledge retention have not remained open. Our aim in this paper is to explore how agency fire

\footnotetext{
${ }^{3}$ By 'traditional' we refer to the time-tested knowledge and customary practice, which still guide these societies.
} 
Eriksen, C. \& Hankins, D. L. (2014) The retention, revival and subjugation of indigenous fire knowledge through agency fire fighting in eastern Australia and California, USA. Society and Natural Resources, 27(12), pp.1288-1303.

fighting and training impacts trajectories of Indigenous fire knowledge retention and

revival. Paramount to our argument is the belief that the continuing legacy of $20^{\text {th }}$

Century fire suppression policies acts against the laws of nature (including ecosystem processes) in many parts of Australia and USA.

\section{Methodology}

The many similarities between NSW, QLD and California - ecological, climate, colonial, and pyro-geographical - invite comparison with one another both historically and contemporarily (Lewis 1989; Hankins 2005; see Mistry 2000 for an argument for broader geographical comparisons). In comparing Indigenous fire knowledge and burning practices across two geographical regions we run the gauntlet of scholarly criticism regarding the portrayal of all Indigenous knowledge as being the same (Smith 2012; Agrawal 1995; Hankins and Ross 2008; Eriksen and Adams 2010). However, in addition to the similarities highlighted above, the approach is supported by the many similarities apparent in the narratives from both regions of Indigenous eco-cultural fire processes. It is outside the scope of this paper to present a comprehensive review of all of the similarities; rather we focus on the knowledge, experiences and reflections of Indigenous community members to examine the ways in which state and federal agency fire fighting impacts on the retention of traditional Indigenous fire knowledge.

More than two-dozen Indigenous Elders, cultural practitioners, and land stewards have shared oral narratives with us over the past decade during participant observation at prescribed burns, fire knowledge workshops (e.g., TKRP 2011), and fieldtrips with students in NSW, QLD and California. In addition, audio-recorded interviews were carried out during 2011 with two Aboriginal employees of the NSW 
Eriksen, C. \& Hankins, D. L. (2014) The retention, revival and subjugation of indigenous fire knowledge through agency fire fighting in eastern Australia and California, USA. Society and Natural Resources, 27(12), pp.1288-1303.

National Parks and Wildfire Service (NPWS) and six California Indian cultural practitioners and/or fire fighters; this includes frontline fire fighters and fire management officers of the US Forest Service (USFS) and the California Department of Forestry and Fire Protection (CALFIRE). It should be noted that not all interview participants currently live or work in the tribal country (homelands) from which they originate. The clan/tribal names of the Indigenous interview participants have not been revealed to ensure their anonymity given overall low Indigenous population figures and their employment status with agencies.

Interviewees were selected purposively in terms of criteria that were central to the main research topic on present-day Indigenous fire knowledge and practices. These criteria include current engagement with fire policy and practice either in a cultural context or through fire fighting; cultural story telling; involvement with natural resource management on Indigenous lands; and Indigenous heritage. The duration of interviews ranged from one to three hours. All interviews were audio recorded and transcribed verbatim before being coded in the Computer Assisted Qualitative Data Analysis Software NVivo v9. The interview transcripts were coded using both $a$ priori themes, such as knowledge of fire, and emerging themes, such as emotional responses.

Narrative analysis facilitated insight into 'structures of knowledge' and 'storied ways of knowing and communicating' (Riley and Harvey 2007). While the term 'narrative' can cover a variety of understandings and a range of oral and text styles, it specifically refers to individual interpretations of events, places, culture and context in this paper (Riessman 2008). Illustrative quotes from the interviews have been included in the text both because they are representative of the findings and as an 
Eriksen, C. \& Hankins, D. L. (2014) The retention, revival and subjugation of indigenous fire knowledge through agency fire fighting in eastern Australia and California, USA. Society and Natural Resources, 27(12), pp.1288-1303.

acknowledgement of the central role of oral story telling as a means of knowledge

sharing and learning amongst California Indian and Aboriginal Australian

communities.

\section{Connecting Indigenous Fire Knowledge with 'Modern' Political Constructs of}

\section{Fire}

A 'disconnect' between the past, present and future of both ecological and cultural aspects of fire underpins a tendency amongst many researchers, policy makers, and practitioners to dismiss or ignore fire knowledge that is alive today amongst Indigenous Elders and cultural land stewards. This may be attributed to assumptions based on historic events, a lack of current burning, and relatively low Indigenous populations in Australia and the USA. Instead guidance is sought from archaeological, anthropological and ethnographic records from the past or from scientific models that project the future. The statement by an Aboriginal NSW NPWS employee below shows how insidious this behaviour is:

"When I started to think about it more, I was actually surprised to find that there is knowledge out there in terms of fire within these [Aboriginal] communities. You would think that due to the heavy impact of colonisation in NSW, even in regional areas, you know, there are old people who have knowledge and who remember stuff from when they were younger. Their stories have been passed down and stuff; it just hasn't been practiced and put into play in that regard. I got this feeling that there was an assumption, you know, that Aboriginal people didn't have the capacity to do this burning or to do this and that, but that's just not the case. You know, a lot of them do have some really good ideas around burning and a lot of them are aware and have an understanding of how the fire 
Eriksen, C. \& Hankins, D. L. (2014) The retention, revival and subjugation of indigenous fire knowledge through agency fire fighting in eastern Australia and California, USA. Society and Natural Resources, 27(12), pp.1288-1303.

management should take place. So, you know, we're not dumb. We definitely

know country." (Male, June 2011)

Similar to the preconceived notions of Indigenous burning described above, there exists an attitude that the historic use of fire by Indigenous people does not apply to the environment today due to environmental and demographic changes (White 2004; Raish et al. 2005; Carroll et al. 2010). It is important to recognise, however, that culture and knowledge are dynamic. From an applied standpoint Indigenous fire knowledge is fluid (for example, changing with past climatic events), and the ability to read the landscape to know how, when, why and what to burn comes with proper training. The concept of 'proper training', however, arguably plays out differently today due to the impact of history and politics. While applied skills in Indigenous fire knowledge still exist in some, frequently remote, communities, most Indigenous people working with fire today in the study areas are predominantly trained within the Eurocentric and patriarchal notion of fire fighting. State and federal fire fighting agencies and men are therefore frequently their main source of fire knowledge. Yet the Indigenous fire fighters we have talked to in NSW, QLD and California see the linkages to traditional Indigenous fire knowledge in present-day prescribed burning practices. Recalling the historical use of fire as a land management tool on his family's ranch in California, this retired California Indian fire fighter pondered the connection:

"In the fall after the first couple of rains, we'd move the cows back to the ranch and we'd light matches on that rangeland. Was that an Indian thing or was that a rangeland management thing? I can't tell you the answer to that. ... Was that Indian culture burning or was that range management? I think sometimes those 
Eriksen, C. \& Hankins, D. L. (2014) The retention, revival and subjugation of indigenous fire knowledge through agency fire fighting in eastern Australia and California, USA. Society and Natural Resources, 27(12), pp.1288-1303.

meshed together culturally. I think the farmers came and they saw the Indians

doing something like that. And when you look at the fire ecology of California, well it's every seven to eleven years there's a fire on every acre. ... I think it was just kind of transitional. Who's culture are you dancing today? Are you dancing to European or Maidu culture? You don't know. So you just dance and move on.” (Male, May 2011)

Given this reflection, it is interesting to note that many California Indians worked as vaqueros (cowboys) or ranch hands following settlement, as this served as a way to stay on one's homeland and establish a place in the new dominant society. Aboriginal people fulfilled a similar role on pastoral stations in Australia following pioneer settlement (Gill 2005; Harrison 2004). Stories handed down from these early days of white settlement frequently noted that in the fall or at the onset of the rainy season Indigenous workers would burn to 'clean up' landscape for the removal of accumulated woody fuels on the ground and facilitate the production of luxuriant grasses, herbs and forbs upon which the livestock would feed in the next grazing season. The practice of 'clean up' burning was a traditional practice among various Indigenous groups, and fell into a suite of burning practices carried out across the seasons and spatial configurations based on the objectives behind fire in a given location. Ultimately, many multi-generational ranching (pastoral) families have continued to burn in this fashion, until the practice largely ceased in California in the 1950s due to policy constraints (e.g., air-quality control and liability of escape).

Just as work on ranches (pastoral stations) provide an avenue for Indigenous people to reconnect with land that they are otherwise denied access to, so too have employment with state and federal wildfire management agencies. While agency burning practices 
Eriksen, C. \& Hankins, D. L. (2014) The retention, revival and subjugation of indigenous fire knowledge through agency fire fighting in eastern Australia and California, USA. Society and Natural Resources, 27(12), pp.1288-1303.

may differ from traditional burning practices and outcomes, employment

inadvertently opens up an avenue for the retention and fortification of elements of Indigenous fire knowledge through interaction with 'country' - albeit in the context of agency wildfire fighting, and not always within one's own home country. An Aboriginal employee of the NSW NPWS spoke of the awe he experienced when he, during an Indigenous-run Traditional Knowledge Revival Pathway (TKRP) fire workshop in the Cape York Peninsula, realised just how complex and interconnected Indigenous ways of caring for country through practices of prescribed burning are with the cycles of nature:

"It was very important not to burn the canopy and you could see that yourself by looking at the fire scars on the trees, you know, they were really low.... An old fella, when we were doing a night burn, told me about the grasses resprouting, like about two or three days after the fire. ... He was talking about the clouds having rain in them but them not dropping that rain. But by burning at night-time, by the morning enough smoke had been put into the atmosphere to make those clouds sweat, to make rain. And when he told me, I sort of sat there and I went, 'So you fellas can control the rain?' And he just looked at me and he said, 'Yeah, we control the rain through fire'. In my nine years of working for National Parks there's not one NPWS fire fighter that's ever blown me away like that and given me something of knowledge for me to sit there in awe of them and say, 'Far out! You really know about fire'. For all their [NPWS] bells, whistles, helicopters and all this modern gear, they never impressed me that much.” (Male, June 2011)

Another Aboriginal fire fighter (in the quote below) linked the well-being of the 
Eriksen, C. \& Hankins, D. L. (2014) The retention, revival and subjugation of indigenous fire knowledge through agency fire fighting in eastern Australia and California, USA. Society and Natural Resources, 27(12), pp.1288-1303.

country with her own personal well-being through working with fire in NSW. This sense of well-being is consistent with the findings of Burgess et al.'s (2005) study of the health-benefits associated with Indigenous burning practices, which included increased physical, mental and social health.

"I like the teamwork and I know it's good for the country, for the land, because we need that fire to let everything grow again. Basically it's an ever-revolving cycle. If we don't have that it's an issue. ... I know some people go because of the financial benefits but I'm neither here nor there. I mean the reward is there of course but it doesn't really faze me the money that you get out of it at all. Like I say, the social aspects and the environmental aspects of it is what I really enjoy.” (Female, August 2011)

This feeling of well-being through agency fire fighting, however, obscures the power struggles and the fluidity of knowledge that underpin the interactions between Indigenous, state and federal laws and management systems. While employment with fire fighting agencies plays an important role in the retention of Indigenous ecocultural fire knowledge, it can also defy cultural laws and practice, which subvert the revival of Indigenous burning practices.

\section{Issues for Cross-Cultural Acceptance}

\section{History Looms Large}

Despite the opportunities gained from employment with wildfire management agencies, history looms large for many Indigenous fire fighters. For the Aboriginal fire fighter quoted below, being an employee of the NSW NPWS over time has made him acutely aware of the historical tensions between freedom and control and access 
Eriksen, C. \& Hankins, D. L. (2014) The retention, revival and subjugation of indigenous fire knowledge through agency fire fighting in eastern Australia and California, USA. Society and Natural Resources, 27(12), pp.1288-1303.

and exclusion in the context of land and wildfire management:

“Because we're employed as conservation land managers, we're the real connection to country in terms of a job. I can't think of too many other jobs really where you get out on country and you're looking after country apart from working for National Parks, you know. And that's not to say that all black fellas love National Parks. That's not the truth at all. There's a lot of black fellas that have a really bad, heavy resentment towards National Parks because they call them 'the Gatekeepers'.... They control our culture physically in terms of access to country, but they also control it legally. Legislatively, the National Parks is responsible for the protection of Aboriginal cultural heritage and a lot of old people especially don't want to see that. They want to take that power back from National Parks and give it back to our people to control. Which I guess National Parks are trying to do by boosting their Aboriginal employment numbers, but still it's in the white man's context. It's returning control and supporting empowerment but only to a limited extent. It's still a space which exists strictly within that Western regime sort of thing." (Male, June 2011)

When we asked an USFS employee if he had found it difficult being a Native American within a federal agency fighting wildfires, he emphasised that the problem rather lies in the need for better cultural fire education both within agencies and within tribal communities.

“Up to this point I really haven’t [found it difficult]. It's just getting [rediscovering and understanding] the native culture that moved out. A fire fighter usually just, you know, I was just out there fighting a fire. Now I'm in the management side, learning the processes. I'm trying to educate the Native 
Eriksen, C. \& Hankins, D. L. (2014) The retention, revival and subjugation of indigenous fire knowledge through agency fire fighting in eastern Australia and California, USA.

Society and Natural Resources, 27(12), pp.1288-1303.

folks when I go home, or when talking with family or friends, to understand that there is a process that we have to follow in order to get what we want done.

That's something that gets a little debatable sometimes. ... I actually volunteer to do a lot of stuff with the Natives [sic] just to help educate. Try and break down some of those barriers and hopefully that light bulb comes on. Sparks don't just come from us. They've been around for a long time. And lightning has been around for a long time and it's one of those things that you've always got to be heads up for.” (Male, May 2011)

Obscured in this short interview excerpt, is the important role this volunteer work has for supporting change cross-culturally. While this California Indian fire fighter did not originate from the tribal country in which he is working, he is using the authority that his USFS training and employment gives him to work with local tribal groups and agency employees to usher in cultural fire education where he can. The lack of co-management agreements between tribal and state or federal entities in California ${ }^{4}$ (a developing practice across Australia) makes this fire fighter a key facilitator in bridging the divide between agency bureaucracy and local tribal interests.

The difference between agencies' emphasis on scientific notions of environmental 'thresholds' in comparison to Aboriginal perceptions of burning as a 'living thing' can be problematic, as highlighted by an Aboriginal NSW NPWS employee:

"When we drove out to Nullumbuy [Northern Territories] we actually saw an old car [with] probably eight traditional people in the car. They're just walking through the country and they're burning. You know, there was burning

\footnotetext{
${ }^{4}$ For a positive exception, see the 2012 Memorandum of Understanding between the Karuk Tribe and the US Forest Service, Six Rivers National Forest Service, and Klamath National Forest (FS Agreement No. 12-MU-110510000-028).
} 
Eriksen, C. \& Hankins, D. L. (2014) The retention, revival and subjugation of indigenous fire knowledge through agency fire fighting in eastern Australia and California, USA.

Society and Natural Resources, 27(12), pp.1288-1303.

everywhere and I love seeing that. Because they've got management of that

land and they know when to burn, what to burn, and what their outputs of that

burning is. I think that we, even we as an agency, still are coming to terms with

thresholds and all this sort of thing. 'Cause it's a scientific notion, I suppose.

Whereas I see Aboriginal burning practices, it's a living thing, do you know what I mean?" (Female, August 2011)

Although these two notions are not mutually exclusive, they nevertheless pose

challenges for wildland fire management, as differences in desired outcomes drive onthe-ground practices. Miller and Davidson-Hunt (2010) provide an interesting angle to this challenge in the context of the role of fire in the creation of Aboriginal cultural landscapes in Canada (see also, Anderson 2005; Lewis 1993).

\section{The Credibility of Different Narratives}

A further example of the on-the-ground challenges of different cultures of wildfire management play out in the concept of 'landscape restoration' and the use of fire as a restoration tool. "What do they consider restored?" the California Indian USFS employee asked when discussing how to put fire back in the Californian landscape to restore it:

"That's one of our old questions, how do you restore it to the condition it was previous when you don't know what the past condition was. Where do you draw the line? Our more desired condition may be different than yours. ... You know, whose landscape pattern do you end up with? ... You can walk through areas and see where they were clear-cut at one time because all the trees are the same size. So even a hundred years ago, how far back do you go? What kind of 
Eriksen, C. \& Hankins, D. L. (2014) The retention, revival and subjugation of indigenous fire knowledge through agency fire fighting in eastern Australia and California, USA. Society and Natural Resources, 27(12), pp.1288-1303.

documentation have we got of what it looked like?" (Male, May 2011)

When the role of stories passed down about those landscapes is mentioned, the

California Indian fire fighter acknowledges that he often relies on the stories that have been handed down to him. Relying on such traditional knowledge, however, puts him in somewhat of a predicament in terms of his agency training.

"A lot of people are afraid to put something down that's a story. Do you know what I mean? Yeah, it was supposed to look like that, but am I going to put my name on that saying this is what it looked like back then? You know, as far as research goes. Because they're going to question the credibility." (ibid)

Despite being a staunch advocate of prescribed burning and the need to re-connect California Indians with the land, this Indigenous fire fighter's line of thinking and ways of doing are also shaped by his long-term employment with the USFS and the prohibitive laws that prevented his Elders and cultural practitioners from applying their fire knowledge when he was a child.

Similar predicaments surfaced in interview conversations about fire as a 'tool' or as a 'living thing' versus fire as a 'hazard' in the context of desired landscapes features at the wildland-urban interface. An Aboriginal fire fighter used the reaction of a predominately white male audience at a fire management conference in NSW to illustrate issues of trust when mixing fire cultures at the wildland-urban interface:

"In the short Traditional Knowledge Revival Pathways video clip, Victor sort of looks straight in the camera and the whole bush is burning behind him and he says, 'People in Australia think fire's dangerous'. When I played that clip at this fire management conference, like the vibe I was getting back from the audience 
Eriksen, C. \& Hankins, D. L. (2014) The retention, revival and subjugation of indigenous fire knowledge through agency fire fighting in eastern Australia and California, USA. Society and Natural Resources, 27(12), pp.1288-1303.

was like they were offended. Like, 'Well it is! Excuse me it is dangerous.

Excuse me you're standing in the middle of the bush in Cape York, we're surrounded by people's homes, life and property.' And that's what it's all about. It's all about life and property and liability. They can't think outside that square to think if we thought about it ecologically and reduced that fuel then there wouldn't be the danger. I think the "R" that's in that acronym [TKRP], you know 'revival', is really important because when you try and explain this to a white audience, and particularly the white fire management, they want to see it. 'Well, where is it? You show me this special formula of Indigenous knowledge that's going to solve everything. Go on, show us now!' It's about reviving. It's about bringing that knowledge back and they're like 'We don't have the money and time. We need real solutions now.' They're not long-term thinkers." (Male, June 2011)

The above discussion highlights how the mixing of fire cultures often are hindered by a lack of cross-cultural trust. Whose narrative is considered credible in what context? The act of integrating Indigenous and agency fire cultures is closely linked to what knowledge is shared with whom and why.

\section{Sharing What with Whom? Cultural Sensitivity on the Fireline}

At the crux of the issues that arise from the historical legacy of colonisation is the problem of sharing the 'right' knowledge with the 'right' people for cross-cultural acceptance (Sarris 1993). A California Indian cultural practitioner voiced this dilemma in her frustrated narrative of attempting to build a cooperative burn plan with the USFS that would address the regeneration of plants for basketry and hazard reduction burns simultaneously: 
Eriksen, C. \& Hankins, D. L. (2014) The retention, revival and subjugation of indigenous fire knowledge through agency fire fighting in eastern Australia and California, USA. Society and Natural Resources, 27(12), pp.1288-1303.

“Unfortunately agencies don't believe in it unless it's in black and white. They

want to see it written down and a lot of our people are not writers. We have always had oral traditions and they are uncomfortable writing or they don't feel they are going to write well enough. Then you have that, 'How much do you want to tell them?' How much do we have to tell them to convince them?

Because sometimes they want to know things they have no right to know. Agencies are just, you know, out of curiosity and they have no right. It's none of their business. Having this information is not going to make any difference to whether they burn or not but you seem to have to prove [the cultural importance of the prescribed burn]. They can't just take your word for it, you have to prove it." (Female, May 2011)

While burns for basketry resources have been conducted by agencies in California in coordination with weavers from different tribal areas, a key problem with many of these burns is that they often do not achieve the desired cultural outcome, as it is done on agency time with agency rules. Few Tribal participants are able to guide it given the certification standards required to be on the fireline. The matter boils down to any burner knowing the cultural reason to burn as well as the ecological outcome given the conditions at hand and species present. This again begs the question of who has the right to know what in order to secure cross-cultural acceptance without compromising the cultural aspects of the tribal hierarchies that underpin Indigenous fire knowledge and burning practices. Black (2011, p. 29) explains that if people live in land foreign to them they must become familiar with the Indigenous cultural knowledge and practices in order to better engage with that landscape. This includes recognition that there is knowledge they are not privy to unless rights to know are specifically given. However, this can obscure cultural sensitivity on the fireline. 
Eriksen, C. \& Hankins, D. L. (2014) The retention, revival and subjugation of indigenous fire knowledge through agency fire fighting in eastern Australia and California, USA. Society and Natural Resources, 27(12), pp.1288-1303.

An example of such cultural sensitivity that was brought up repeatedly during interviews is the impact of wildfire and fire fighting on Indigenous sacred sites and other areas of significance. Just as knowledge of fire has been retained, so too has the knowledge of cultural sites. Indigenous laws governing access to such sites are often related to an individual's own role within their society. For some areas access may be linked entirely to gender or may be restricted to initiation into a given society. In modern society the implementation of prescribed fire and/or the suppression of wildfire may bring conflict with the traditional practices of a given group. Thus knowing where, when, what, and how to burn is one set of attributes governing traditional fire, but knowing the deeper significance of the landscape is key to securing appropriate cultural context and sensitivity awareness. The disrespect or lack of cultural knowledge within agencies has led to instances where Aboriginal cultural heritage has been dismissed to ease the logistics of fire fighting operations. For example, when a helicopter used an Aboriginal rock art site as a landing pad, one Aboriginal firefighter felt the site was being "desecrated". This discussion also relates to the lack of appreciation of Indigenous knowledge and concerns, discussed earlier. The lack of cultural concern by fellow fire fighters was a further concern:

"I've been on a fire at [name] National Park where there's a rock overhang with white ochre hand stencils in it and it's a really well known site. ... When we started to burn, back burn I think it was, no it might have been a wildfire. Anyway, doesn't matter, the point is, we had a lunch break and we're all sitting around this table and I said, 'There's a site just up there, does anyone know if the fire got up into it?' and everyone just sort of looked at me, like 'That's so irrelevant'. And I said, 'Well, I'm going to go up there and have a look and check" and I was actually laughed at. Like a few of them laughed at me and 
Eriksen, C. \& Hankins, D. L. (2014) The retention, revival and subjugation of indigenous fire knowledge through agency fire fighting in eastern Australia and California, USA. Society and Natural Resources, 27(12), pp.1288-1303.

giggled like, 'Oh that's just so, who gives a shit about that site.' You know what

I mean, like that's got nothing to do with the fire and if it got burnt, it got burnt and that was their attitude." (Male, June 2011)

Another Aboriginal fire fighter spoke of her frustration with the lack of consideration for cultural heritage sites as part of the planning stages of fire fighting operations:

"When I've been on IMTs [Incident Management Teams], and even on the ground, I get frustrated about the lack of planning, even in a wildfire situation, that we do in relation to the protection of things. Like hollows and rake hoeing around larger trees to protect the base, which is the integrity of the whole tree itself. The lack of work that we do in that respect and also the lack of work that we do in relation to the protection of Aboriginal heritage sites. I have never gone to a fire, no I take that back, I've been to one fire, a big incident at [name], where I know that, and I'll refer to him as one of my Elders, insisted on being winched in along the rivers to check for scar trees ${ }^{5}$ for protection from the fire. I've never been to another fire where there's been mention of it or thoughts in people's heads they've got to do this. And that's really irritated me." (Female, August 2011)

That respect for sacred ground and cultural practices, including the acknowledgement of who has the right to access those places, is largely overlooked by agencies is an interesting dilemma in that if traditional burning practices were in place, then the right people would inherently be burning the places they were obligated to care for. However, since policy does not support such practice, the reality of having damaging

\footnotetext{
${ }^{5}$ Aboriginal scarred trees are trees that have been scarred through the deliberate removal of bark or wood for the construction of shelters, canoes, etc. Scarred trees are an important record of traditional place and events in the history of many Indigenous peoples (Long 2005; Turner et al. 2009).
} 
Eriksen, C. \& Hankins, D. L. (2014) The retention, revival and subjugation of indigenous fire knowledge through agency fire fighting in eastern Australia and California, USA. Society and Natural Resources, 27(12), pp.1288-1303.

fires scorch sacred ground is often only overcome by fire suppression by whoever is appointed by the agency to do so.

It is interesting that experiences to the contrary - of agency fire operations considerate of Indigenous gendered landscapes - have been shared specifically by female nonAboriginal staff members of the NSW NPWS. One white female NSW NPWS fire fighter, for example, narrated how at one fire the on-the-ground fire units were organised so only men would patrol the fire on a site sacred to Aboriginal men. Can this heightened awareness by some white female fire fighters be explained by a greater sensitivity towards other minority groups given women's minority status within the male-dominated world of fire fighting? The answer could be both yes and no. Pease (2010) points out that whilst awareness of experiences of oppression are much more common than consciousness of aspects of one's own privileges, members of dominant groups are at the same time conditioned by the normalisation of inequality. Privilege seems natural because processes of oppression are normalised in everyday life through habituated and unconscious practices. Many do therefore not recognise aspects of their own privilege as the cultural norms and bureaucratic institutions in which privilege is embedded legitimate it. Thus women within the male-dominated sphere of fire fighting are continually reminded of how their gender is a source of discrimination through the habituated and unconscious practices of many male colleagues (Enarson 1984; Eriksen, In press). This may heighten their consciousness of other forms of oppression in their everyday lives. However, white female fire fighters are simultaneously privileged by their race, which may alienate some Indigenous women from this 'alliance' (Black 2011). 
Eriksen, C. \& Hankins, D. L. (2014) The retention, revival and subjugation of indigenous fire knowledge through agency fire fighting in eastern Australia and California, USA. Society and Natural Resources, 27(12), pp.1288-1303.

The privilege and opportunity to engage in activities that ultimately support

connections to country may ironically conflict with cultural stewardship practices.

Privilege is not simply something people have the option of taking or relinquishing because it is socially constructed and operates on personal, cultural, as well as structural levels (Pease 2010). That Indigenous fire fighters (and others) can be both oppressed and privileged at the same time highlights the complex ways in which privilege intersects with oppression. The following example illustrates the importance of Indigenous fire fighters reflecting critically on their own position to aid crosscultural understanding and acceptance. The racial tension described by the Aboriginal fire fighter below is a poignant example of the entwined nature of ethnicity, gender, class, and age described by research participants in NSW, QLD and California alike. The fine line between right and wrong in the interactions of the fire unit's crewmembers, and in the context of conservation and wildfire management, resulted in open conflict when a non-Indigenous field officer agreed to widen the stipulated size of an Asset Protection Zone (APZ) (fuelbreak) on a friend's private property neighbouring a national park in NSW.

"I didn't know that that was going on but the Aboriginal girl that I was working with did know and she put her chainsaw down and took her protective gear off and said, 'No way! I'm not doing this.' She said, 'Where's your REF [Review of Environmental Factors] or your Environmental Impact Statement. You can't just widen an APZ just because you're good mates with this bloke and now he wants it a bit wider. There's no Cultural Heritage Survey. This is virgin bushland. How do you know that that tree isn't scarred or this and that?' ... She stood her ground and said no and they were sort of looking at me like, 'Well come on [name], what do you think?' Her and I were the only two Aboriginal people 
Eriksen, C. \& Hankins, D. L. (2014) The retention, revival and subjugation of indigenous fire knowledge through agency fire fighting in eastern Australia and California, USA.

Society and Natural Resources, 27(12), pp.1288-1303.

there and I said, 'No, there's no way ... I'm going to stand by my people. If she's not going to do that,' I said, 'I'm with her before I'm with you...' and I put my tools down too and said no.... That blew up into a huge thing. ... Disciplinary Action, the whole bit because you're trying to fight them and you're only young and you get frustrated and all that. ... It becomes like an Industrial Workplace Issue where we're causing trouble and I'm being violent because I'm raising my voice and everything, when really it's them that were raping the land and doing the exact opposite of what they're supposed to do. They're supposed to be protecting natural and cultural heritage, not chopping it down just to please some fella.” (Male, June 2011)

This Aboriginal fire fighters experience during a day at work in the woods highlights how '...in everyday interactions dominance may be reinforced just because of belonging to a dominant group by birth' (Pease 2010, p. 11). Privilege - or the lack thereof - arguably underpins the suspicion or hostility expressed by many Indigenous peoples both in our study and more generally towards wildfire management agencies. Although non-Indigenous men make up the majority of employees in these agencies, male and female, Indigenous and non-Indigenous employees alike are inherently members of a 'privileged group' through their employment with institutions founded on colonial constructs of power. State and federal agencies create privilege through access to land, which simultaneously facilitates shifts in the experience and living knowledge of fire. Thus whilst many well-meaning fire fighters are opposed to cultural oppression, it is incomprehensible to many how they inadvertently benefit from the practices that they claim to oppose. The implications of this for crosscultural acceptance and the integration of Indigenous and agency fire cultures have been and continue to be severe. 
Eriksen, C. \& Hankins, D. L. (2014) The retention, revival and subjugation of indigenous fire knowledge through agency fire fighting in eastern Australia and California, USA.

Society and Natural Resources, 27(12), pp.1288-1303.

\section{Conclusion}

This paper illustrates that traditional Indigenous fire knowledge and burning practices are retained, revived as well as subjugated through the fire management policies and practices of state and federal agencies in NSW, QLD and California. While this study only represents segments of the Indigenous populations within our regions of interest, it establishes a critical baseline of existing fire knowledge and memories retained by Indigenous Elders, cultural practitioners, and land stewards. This baseline of knowledge highlights that there is far more at stake than just managing the risk of wildfire. Integration of cultural perspectives of fire provides Indigenous peoples with the opportunity to engage with the restoration of healthy environments. Doing so can revitalise cultures by linking people with natural resource production for food and other cultural practices, as well as active engagement with patterns of land use and occupancy that have been weakened by changing ecosystems and urban expansion. Ultimately reengaging with fire through their own Indigenous knowledge allows Indigenous peoples in NSW, QLD and California to reengage as caretakers of their native lands.

The paper also highlights how the troubled history between Indigenous peoples and colonial processes continues to impact cross-cultural interactions and acceptance amongst Indigenous and non-Indigenous fire fighters within wildfire management agencies. While we cannot reverse the history of colonisation, we can still learn from the fire knowledge both Indigenous and non-Indigenous cultures have to share. The retention, revival and integration of the Indigenous fire knowledge discussed in this paper seems to hold many lessons, which can be used to aid ongoing debates on how to coexist with wildfire today. The paper shows the need for cultural sensitivity 
Eriksen, C. \& Hankins, D. L. (2014) The retention, revival and subjugation of indigenous fire knowledge through agency fire fighting in eastern Australia and California, USA.

Society and Natural Resources, 27(12), pp.1288-1303.

training for firefighters, the importance of developing policies to instil the recognition

of cultural norms, as well as the impact of not having such training and policies in

place. As on the ground actors for land management institutions, the cultural

awareness and responsiveness of firefighters greatly impact on how formal policy is

enacted. Perhaps most importantly in light of Indigenous knowledge systems is that in working together with Indigenous communities, state and federal agencies stand to gain through the protection and enhancement of a real asset at risk: the cultures which have shaped the landscapes of Australia and the USA since time immemorial. In light of this comes the recognition that when Indigenous people have not actively asserted customary law and applied fire to care for country, the laws of nature continue to play out through wildfires. Indigenous practice inherently has recognised the country "speaking" its needs through wildfire. This recognition drives the implementation of Indigenous prescription of fire. We believe a greater recognition of this traditional understanding of the environment could aid current struggles to manage the growing frequency of devastating wildfires if it is acknowledged by, and incorporated into, the practices of wildfire management agencies.

\section{References}

Agrawal, A. 1995. "Dismantling the Divide Between Indigenous and Scientific Knowledge." Development and Change 26:413-439.

Anderson, M. K. 2006. Tending the Wild: Native American Knowledge and the Management of California's Natural Resources. Berkeley: University of California Press. 
Eriksen, C. \& Hankins, D. L. (2014) The retention, revival and subjugation of indigenous fire knowledge through agency fire fighting in eastern Australia and California, USA.

Society and Natural Resources, 27(12), pp.1288-1303.

Bird, D. W., R. Bliege Bird, and C. H. Parker. 2004. "Women who hunt with fire:

Aboriginal resource use and fire regimes in Australia's Western Desert." Australian Aboriginal Studies 1:90-96.

Black, C. F. 2011. The Land is the Source of the Law: A Dialogic Encounter with Indigenous Jurisprudence. London: Routledge.

Brody, H. 2002. The Other Side of Eden: Hunter-Gatherers, Farmers and the Shaping of the World. London: Faber and Faber.

Burgess, C. P., F. H. Johnston, D. Bowman, and P. J. Whitehead. 2005. "Healthy Country: Healthy People? Exploring the health benefits of Indigenous natural resource management." Australian and New Zealand Journal of Public Health $29(2): 117-122$.

Carroll, M. S., P. J. Cohn, T. B. Paveglio, D R Drader, and P J Jakes. 2010. "Fire Burners to Firefighters: The Nez Perce and Fire." Journal of Forestry 108 (2):71-76.

Childs, M. 2006. "Counting Women in the Australian Fire Services." The Australian Journal of Emergency Management Vol. 21 (2):29-34.

Christianson, A., T. K. McGee, and L. L'Hirondelle. 2012. "How historic and current wildfire experiences in an Aboriginal community influence mitigation preferences." International Journal of Wildland Fire Vol. Published online: 26 October 2012.

Claudie, D. 2009. Northern Kaanju Ngaachi: Linking Cultural \& Biological Diversity. Chuulangun Aboriginal Corporation, Queensland (accessible via http://www.youtube.com/watch?v=5YG5FrnEwyU). 
Eriksen, C. \& Hankins, D. L. (2014) The retention, revival and subjugation of indigenous fire knowledge through agency fire fighting in eastern Australia and California, USA. Society and Natural Resources, 27(12), pp.1288-1303.

Davidson, P., and R. Black. 2001. "Women in Natural Resource Management:

Finding a More Balanced Perspective." Society \& Natural Resources Vol. $14: 645-656$.

Enarson, E. P. 1984. Woods-Working Women: Sexual Integration in the U.S. Forest Service. Alabama: The University of Alabama Press.

Eriksen, C. In press. Gender and Wildfire: Landscapes of Uncertainty. New York: Routledge. ISBN: 978-0-415-50270-2.

Eriksen, C. and M. Adams. 2010. "Indigenous Environmental Knowledge." In Encyclopedia of Geography, edited by Barney Warf, 1564-1567. Thousand Oaks, Calif.: SAGE Publications.

Gammage, B. 2011. The Biggest Estate on Earth: How Aborigines made Australia. Sydney: Allen \& Unwin.

Gill, N. 2005. "Aboriginal Pastoralism, Social Embeddedness and Cultural Continuity in Central Australia." Society and Natural Resources 18:1-16.

Hankins, D. L. 2005. Pyrogeography: Spatial and Temporal Relationships of Fire, Nature, and Culture, PhD Thesis, University of California, Davis.

_ 2009. "The Effects of Indigenous Prescribed Fire on Herpetofauna and Small Mammals in Two Central Valley California Riparian Ecosystems." The California Geographer 49:31-50.

Hankins, D. L. and J. Ross. 2008. "Research on Native Terms: Navigation and Participation Issues for Native Scholars in Community Research." In Partnerships for Empowerment: Participatory Research for Community-based Natural Resource Management, edited by C. Wilmsen et al., 239-257. London: Earthscan. 
Eriksen, C. \& Hankins, D. L. (2014) The retention, revival and subjugation of indigenous fire knowledge through agency fire fighting in eastern Australia and California, USA.

Society and Natural Resources, 27(12), pp.1288-1303.

Harrison, R. 2004. Shared landscapes: Archaeologies of attachment and the pastoral

industry in New South Wales. Sydney: University of New South Wales Press.

Hawkes, A. 2011. Pinnacles tests out tribe's fire tradition. Bay Nature, 25 April 2012. Http://baynature.org/articles/web-only-articles/pinnacles-tests-out-tribes-firetradition (accessed 2 May 2012).

Jensen, S. E., and G. R. McPherson. 2008. Living with Fire: Fire Ecology and Policy for the Twenty-first Century. Berkeley: University of California Press.

Lake, F. K. 2007. Traditional Ecological Knowledge to Develop and Maintain Fire Regimes in Northwestern California, Klamath-Siskiyou Bioregion: Management and Restoration of Culturally Significant Habitats, $\mathrm{PhD}$ thesis, Oregon State University, Corvallis.

Lewis, H. T. 1989. "A Parable of Fire: Hunter-Gatherers in Canada and Australia." In Traditional Ecological Knowledge: A Collection of Essays, edited by R. E. Johannes, 7-20. Gland, Switzerland: IUCN, The World Conservation Union.

Lewis, H. T. 1993. "Patterns of Indian burning in California: ecology and ethnohistory." In Before the Wilderness: Environmental Management by Native Californians, edited by T. C. Blackburn and M. K. Anderson, 55-116. Menlo Park: Ballena.

Lewis, H. T. and T. A. Ferguson. 1988. "Yards, Corridors, and Mosaics: How to Burn a Boreal Forest." Human Ecology 16 (1):57-77.

Long, A. 2005. Aboriginal Scarred Trees in New South Wales: A Field Manual Hurstville: Department of Environment and Conservation (NSW).

Miller, A. M., and I. Davidson-Hunt. 2010. "Fire, Agency and Scale in the Creation of Aboriginal Cultural Landscapes." Human Ecology Vol. 38 (3):401-414. 
Eriksen, C. \& Hankins, D. L. (2014) The retention, revival and subjugation of indigenous fire knowledge through agency fire fighting in eastern Australia and California, USA. Society and Natural Resources, 27(12), pp.1288-1303.

Pacholok, S. 2009. "Gendered Strategies of Self: Navigating Hierarchy and

Contesting Masculinities." Gender, Work \& Organization Vol. 16 (4):471-500

Pease, B. 2010. Undoing Priviledge: Unearned Advantage in a Divided World. London: Zed Books.

Pyne, S. J. 1997. World Fire: The Culture of Fire on Earth. Seattle: University of Washington Press.

Raish, C., A. Gonzalez-Caban, and C. J. Condie. 2005. "The importance of traditional fire use and management practices for contemporary land managers in the American Southwest." Environmental Hazards 6:115-122.

Riessman, C. K. 2008. Narrative methods for the human sciences. Thousand Oaks: Sage Publications.

Riley, M. and D. Harvey. 2007. "Oral histories, farm practice and uncovering meaning in the countryside." Social \& Cultural Geography 8 (3):391 - 415.

Sarris, G. 1993. Keeping Slug Woman Alive. Berkeley and Los Angeles, CA: University of California Press.

Smith, Linda Tuhiwai. 2012. Decolonizing methodologies: research and indigenous peoples. $2^{\text {nd }}$ Edition. Dunedin, N.Z.: University of Otago Press.

Stephens, S. L., R. E. Martin, and N. E. Clinton. 2007. "Prehistoric fire area and emissions from California's forests, woodlands, shrublands, and grasslands." Forest Ecology and Management 251:205-216.

Stewart, O. C., H. T. Lewis, and M. K. Anderson. 2002. Forgotten Fires: Native Americans and the Transient Wilderness. Norman: University of Oklahoma Press.

Suchet, S. 2002. "'Totally Wild'? Colonising discourses, indigenous knowledges and managing wildlife." Australian Geographer Vol. 33 (2):141-157. 
Eriksen, C. \& Hankins, D. L. (2014) The retention, revival and subjugation of indigenous fire knowledge through agency fire fighting in eastern Australia and California, USA. Society and Natural Resources, 27(12), pp.1288-1303.

TKRP. 2011 Traditional Knowledge Revival Pathways. Http://www.tkrp.com.au (accessed 16 January 2012).

Turner, N. J., Y. Ari, F. Berkes, I. Davidson-Hunt, Z. F. Ertug, and A. Miller. 2009. "Cultural Management of Living Trees: An International Perspective." Journal of Ethnobiology Vol. 29 (2):237-270

Vigilante, T., B. Murphy, and D. Bowman. 2009. "Aboriginal fire use in Australian tropical savannas: Ecological effects and management lessons." In Tropical Fire Ecology: Climate Change, Land Use, and Ecosystem Dynamics, edited by M. A. Cochrane. Springer.

White, G. 2004. "Restoring the Cultural Landscape." In American Perspectives on the Wildland/Urban Interface, edited by National Wildland/Urban Interface Fire Program, 25-29. Quincy, MA: FirewiseCommunities/USA. 